\title{
ERGONOMİK MONTAJ HATTI DENGELEME
}

\author{
Adil BAYKASOĞLU, Şebnem DEMİRKOL AKYOL \\ Dokuz Eylül Üniversitesi Endüstri Mühendisliği Bölümü, Tınaztepe Yerleșkesi 35397 Tınaztepe / Buca / İZMİR \\ adil.baykasoglu@deu.edu.tr, sebnem.demirkol@deu.edu.tr
}

(Geliş/Received: 03.12.2013; Kabul/Accepted: 04.09.2014)

\begin{abstract}
ÖZET
Montaj hattı dengeleme probleminde işler, öncelik ilişkilerine uygun olarak toplam işlem sürelerini mümkün mertebe dengeleyecek şekilde istasyonlara atanır. Ancak, istasyonlardaki toplam işlem sürelerinin düzgün dağılması tek başına çok fazla anlam ifade etmeyebilir. Diğer bir değişle, işlem süreleri eşit olan iki farklı istasyondaki işler birbirinin tıpatıp aynısı olmayacağından, bu istasyonlardaki zorlanma dereceleri de farklılık gösterebilir. Bu durum her ne kadar klasik montaj hattı dengelemede göz ardı edilse de, gerçek hayat uygulamalarında büyük önem arz eder. Özellikle emek yoğun çalışılan montaj hatlarında, bir istasyonda, benzer işlerin tekrarlı olarak uzun süre yapılması neticesinde işçi üzerindeki zorlanma giderek artar. Ergonomik anlamda iyi tasarlanmamış montaj hatları, yalnızca verimlilik kayıplarına sebep olmakla kalmaz, işçilerde meslek hastalıklarına ve hatta kalıcı hasarlara yol açabilir. Bu tarz olumsuzlukları önlemek için montaj hattını dengelerken her bir istasyon için kabul edilebilecek en yüksek risk seviyesini belirlemek ve ergonomik risk faktörlerinin bu seviyenin üstüne çıkmasına izin vermemek gerekir. Bu çalışmada, ergonomik risk seviyesi belirlemede son derece etkin bir yöntem olan OCRA indeksi tanıtılmıştır. Yöntemde kullanılan parametrelere detaylıca yer verilmiş ve bir uygulama üzerinde anlatılarak ergonomik risk faktörlerini dikkate alarak tasarlanan montaj hattı ile klasik yaklaşımla tasarlanan hat arasındaki farklar vurgulanmıştır.
\end{abstract}

Anahtar Kelimeler: Ergonomik risk faktörleri, Montaj istasyonu, OCRA indeksi

\section{ERGONOMIC ASSEMBLY LINE BALANCING}

\begin{abstract}
Tasks are distributed among workstations as smooth as possible in accordance with the precedence relations in assembly line balancing. However, just smoothening the total station time between stations can be meaningless in many industrial circumstances. In other words, two stations whose total station times are equal may contain tasks with different ergonomic loads. Consequently, their degrees of strain can be very different. This situation is underestimated in classical assembly line balancing, but it is an important aspect in reality. Especially in manual assembly lines, same type of work is done by the operator repetitively. As a result, there is a cumulative effect of repetitive work on worker. Assembly lines which are not well-designed ergonomically, cause not only lack of productivity, but also occupational diseases of workers. In order to prevent these complications, the acceptable risk level for a station should be analyzed and ergonomic risk factors of the station must be below this highest acceptable level. OCRA index, which is a very efficient procedure for ergonomic risk assessment, is explored in this study. The parameters of the method are explained in detail, and a comparison between ergonomically designed and non-ergonomic assembly line and is presented.
\end{abstract}

Key words: Ergonomic risk factors, Assembly station, OCRA index

\section{GİRİS (INTRODUCTION)}

Montaj hatt1 dengeleme problemi (MHDP), öncelik ilişkileri diyagramı ile birbirine bağlanmış ve belirli işlem sürelerine sahip olan işlerin çeşitli performans kriterlerini eniyileyecek şekilde istasyonlara atanmasıdır. MHDP, ortaya çıkışından itibaren [10] bilim insanları tarafindan araştırılmış ve MHDP'nin çeşitli alanlarında çalışmalar yapılmıştır. Klasik montaj hattı dengelemede genel olarak, işleri istasyonlara dağıtırken problemin tipine göre ya iş istasyonu sayısı (I. tip) ya da çevrim süresi (II. tip) 
enküçüklenmeye çalışılır. $\mathrm{Bu}$ atama sırasında istasyonların toplam işlem süreleri olabildiğince birbirine yakın tutulmaya çalışılır ki istasyonlar arasındaki iş yükü düzgün dağılmış olsun. Fakat istasyonlar arasındaki iş yükünü düzgün dağıtmak için yalnızca işlerin operasyon zamanlarını dikkate almak çoğu durumda yeterli değildir. Aynı zamanda işçilerin zorlanma derecelerini de mümkün olduğunca eşit tutmak gerekir. Aksi takdirde, birtakım işçilerde aşırı yüklenme oluşması sonucu çeşitli verimlilik ve işgücü kayıpları, uzun dönemde ise meslek hastalıkları ve kalıcı hasarlar oluşabilir.

İşyerinde yapılan aktiviteler sırasında çeşitli risklere maruz kalma sonucunda gelişen hastalıklara genel olarak meslek hastalıkları denir. Ülkeden ülkeye değişmekle birlikte, y1lda her 1.000 işçiden 4-12'sinin meslek hastalığına yakalanma olasılığı bulunur. $\mathrm{Bu}$ varsayıma göre, ülkemizde beklenen meslek hastalığ 1 vakas1 40.000-80.000 arasındadır. Ancak, 2012 yılında saptanan olgu sayısı yalnızca 395 'tir $[3,5]$. Bu veriler, vakaların büyük çoğunluğunun tanı konulamadan kaybolup gittiğini gösterir ki bu son derece kötü bir tablodur. Çünkü bir işçide oluşan meslek hastalığına tanı konulması demek, aynı zamanda iş ile ilgili gerekli tedbirleri alarak, o işçinin çalışma arkadaşlarının aynı hastalığa yakalanmasını önlemek demektir. Bu konudaki bir diğer önemli nokta ise kayda geçen 395 vakadan hiçbirinin kasiskelet sistemi hastalıkları (KISSH) grubuna girmemesidir. Oysaki gelişmiş ülkelere bakıldığında KİSH, meslek hastalıklarının önemli bir bölümünü oluştururlar. Ülkemizde kayıtlara geçmeyen meslek hastalıklarının yaklaşık \%40'ının KİS ile ilgili olduğu tahmin edilmektedir. KİSH iş ortamının ergonomik yetersizlikleri sonucu oluşur. Bu durum ülkemizde ergonomik çalışma koşullarına ne ölçüde önem verildiğinin bariz bir göstergesidir. Ergonomik çalışma koşulları sağlamanın önemini ve ortam ergonomisinin yetersizliği sonucunda oluşabilecek zararları bilmek, bu zararları önlemenin bir numaralı kuralıdır.

Ergonomi disiplini, çalışma ortamının iş gören üzerinde fiziksel ve psikolojik etkilerini incelemektedir. Ergonomi prensipleri; kolay ve hıll işlem için iş alanlarının tasarımında, operatörler ve makineler arasındaki görev dağılımını içeren iş metotlarının düzenlenmesinde kullanılır. Özellikle emek yoğun üretim yapılan montaj hatlarında, işlerin tekrarlı olarak uzun süre ve uygun olmayan postur ile yapılmasından dolayı işçilerde parmak tabanında kireçlenme, kayakçı başparmağı, tetik parmak, tenisçi dirseği, karpal tünel, bağ yaralanması, tendinit gibi el, bilek, dirsek ve omuzla ilgili çeşitli meslek hastalıkları oluşur. $\mathrm{Bu}$ hastalıklar oluştuktan sonra tedavileri zaman almakta ve işletmelerde işgücü kayıpları ile birlikte verimlilik kayıplarına da sebep olmaktadır. $\mathrm{Bu}$ nedenle, iş ortamındaki ergonomik risk faktörlerinin bilincinde olarak ve bu faktörlerin belirli bir standart seviyenin üstüne çıkmasına izin vermeyerek bu tür kayıplar ve hastalıklar büyük ölçüde önlenmiş olur.

Montaj hatlarının tasarımında ergonomik risk faktörlerinin dikkate alınması bu denli önemli olmasına rağmen, akademik camiada yeteri kadar rağbet görmemiştir. $\mathrm{Bu}$ konuyla ilgili çok fazla çalışma yayınlanmamasına rağmen, literatürdeki ilgili çalışmalar burada kısaca özetlenmiştir. Vieira ve Kumar [13] tarafindan yapilan yayın taraması çalışmasında ergonomik anlamda çalışma duruşunu (postur) tanımlanarak, bilimsel literatürde bu konuda az sayıda çalışma olduğuna dikkat çekilmiştir. Bahsi geçen çalışmada, bilgisayar başı çalışanı, şoför, depolama çalışanı, maden işçisi, inşaat işçisi, boyacı gibi farklı işlerdeki insanların çalışma duruşlarını analiz eden yayınlar incelenmiştir. Ergonomik çalışma koşullarının verimliliğe etkisini en güzel ortaya koyan çalışmalardan biri Moreau [9]'nun yayınıdır. Otomotiv sektöründe faaliyet gösteren bir montaj hattında çalışma ortamı iyileştirilmiş ve sonuçta bitmiş ürünün çevrim süresinde $\% 30$ 'luk bir iyileşme sağlanmıştır. Battini vd. [1]'nin çalışmasında ergonomi ile montaj hattı konfigürasyonunun gerçek işletme şartlarında birbiriyle ne kadar bağlantılı olduğunu gösterilmiştir. Ele alınan gerçek hayat problemine, önerilen yöntem uygulanmış ve üretkenlikte $\% 15^{\prime}$ lik bir artış, işçi yorgunluklarında ve yaralanmalarında da azalma kaydedilmiștir. Longo vd. [6] tarafindan yayınlanan makalede ise isitici üretimi yapılan bir montaj hattı ele alınmıştır. İki aşamalı bir çözüm önerilmiş; birinci aşamada üretilecek ürünün ve montaj hattının tasarımı yapılmıştır. İkinci aşamada ise, probleme insan faktörü eklenmiş ve ergonomik analizler yapılmıştır. Benzetim tekniği kullanılarak çeşitli sistem modifikasyonları denenmiş ve ergonomik riskleri en aza indiren iş atamaları belirlenmiștir. Diğer yayınlara nazaran daha güncel olan Otto ve Scholl [8]'un çalışmasında ise MHDP-1 problemi ergonomik riskleri azaltacak şekilde yeniden dengelenmiştir. Otomotiv endüstrisindeki bir firmanın montaj hattı önerilen yöntemle yeniden dengelenmiş ve problemlerin \%50'sinde ekstra bir iș istasyonuna ihtiyaç duyulmadan ergonomik riskler kabul edilebilir düzeye çekilmiştir.

$\mathrm{Bu}$ çalışmanın temel motivasyon kaynağı, MHDP'lerinde ergonomik faktörlerin etkisinin son derece önemli olmasına karşın, literatürde bu alanda oldukça sınırlı sayıda çalışma yapılmış olmasıdır. Makalenin içeriği şu şekilde devam etmektedir. 2. kısımda montaj hatlarında ergonomik risk faktörlerini hesaplamak için kullanılan çeşitli yöntemler tanitılacak ve OCRA indeksi yöntemine karar verilmesinin nedenleri açıklanacaktır. 3. Kısımda OCRA indeksi hesaplaması ve parametrelerine yer verilecektir. 4. kısımda verilen sayısal örnek sayesinde çözüm yöntemi daha anlaşılır hale getirilecektir. Son kısımda ise değerlendirmeler ve yorumlara yer verilecektir. 


\section{ERGONOMIKK RISSKLERIN ANALIZZLERDE KULLANILAN YÖNTEMLER VE OCRA METODU (ERGONOMIC RISK ASSESSMENT TECHNIQUES AND OCRA METHOD)}

Çalışma ortamında oluşan ergonomik risk faktörlerini belirlemek için literatürde çeşitli yöntemler mevcuttur. $\mathrm{Bu}$ yöntemlerden en önemlileri: Hızlı Maruziyet Değerlendirme (HMD), Ulusal İș Güvenliği ve Sağlığı Enstitüsü Yöntemi (NIOSH), Hızlı Üst Vücut Değerlendirmesi (RULA), Hızlı Tüm Vücut Değerlendirmesi (REBA), Avrupa Montaj Analizi (EAWS), Mesleki Tekrarlamalı Hareketler İndeksi (OCRA) vb. dir. Bu çalışma kapsamında literatürde bahsi geçen tüm ergonomik risk değerlendirme yöntemleri incelenmiş, özellikleri ve kullanım alanları belirlenmiştir.

Özellikle montaj hattı gibi işçinin gün boyu aynı işleri tekrarlı yaptığı durumlar için ergonomik risk analizi yapılırken, işlerin tekrarlanmasından kaynaklanan kümülatif etkiyi hesaplamak oldukça önemlidir. Yukarıda bahsi geçen ergonomik risk değerlendirme yöntemleri arasından yalnızca OCRA ve EAWS teknikleri bu kümülatif etkiyi dikkate almaktadır. Diğer yöntemlerde her bir iş için ayrı-ayrı risk analizi yapılırken, OCRA ve EAWS yöntemleri tekrarlı işlerin ardı ardına yapılmasından kaynaklı yorulmaları hesaplar. EAWS yönteminin ortaya çıkışının oldukça yeni olmasından kaynaklanan bir takım eksiklikleri mevcuttur. Henüz yöntemin hesaplama prosedürleri ile ilgili ayrıntılı bilgiler içeren çalışmalar yayınlanmamıştır.

OCRA (OCcupational Repetitive Actions) yönteminin ilk gündeme gelişi ise çok daha eskidir [7] ve günümüze kadar literatürde bu yöntemle yapılan birçok çalışma sunularak yöntemin bilimselliği ispatlanmıştır. Bu sebeple, OCRA yöntemi montaj hattında ergonomik risk faktörlerinin analizi için uygun olan tek yöntem olarak ortaya çıkmaktadır. OCRA yönteminde bir istasyonda yapılan tüm işler için kümülatif bir analiz yapılır. OCRA indeksi hesaplanırken istasyonda birden fazla iş yapılıyorsa, bu işler için ayrı-ayrı indeks hesaplanmaz, tüm istasyon için tek bir OCRA değeri hesaplanır. Bu sayede işlerin birbirleri üzerindeki kümülatif etkisi göz ardı edilmemiş olur. OCRA yöntemi kaldırma ve taşımaların yoğun olduğu üretim aşamaları için uygun değildir. Daha ziyade otomasyona dayalı malzeme aktarma sistemlerinin kullanıldığ 1 ve operatörlerin belirli bir hızla ilerleyen bir konveyör etrafında çalıştığı durumlarda kullanılır. OCRA yönteminde üst vücut hareketlerinin ergonomik incelemesi yapılır. Özellikle el, bilek, dirsek ve omuz gibi temel üst vücut elemanlarının çalışma duruşları ve hareketleri OCRA indeksi ile yorumlanmaktadir.

\section{OCRA INDEKSİ PARAMETRELERİ (OCRA INDEX PARAMETERS)}

OCRA yöntemi sıklıkla ve tekrarlanan taşımaların hesaplamasında kullanılan bir ergonomik riskleri hesaplama yaklaşımıdır [7]. Özellikle el, bilek, dirsek ve omuz gibi üst vücut hareketleri ile ilgili hesaplamalar için kullanılır ve vücudun sağ ve sol kısımları için ayrı-ayrı hesaplanır. OCRA indeksi iş süresince gerçekleşen teknik hareket sıklığının, önerilen sıklığa bölünmesi olarak ifade edilir:

$$
\begin{aligned}
& \text { OCRA indeksi = Teknik hareket sıklı̆gl / Önerilen } \\
& \text { sıklık }
\end{aligned}
$$

OCRA literatüründe tekrarlı iş olarak geçen işler, çevrim süresi boyunca tekrarlı olarak yapılan işlerdir. Teknik hareketler ise bir işlemi gerçekleştirmek için yapılan temel manüel hareketlerdir (hareket ettirme, uzanma, alma, kavrama, tutma, bırakma, yürüme, kontrol etme, döndürme, itme, çekme, kesme, başlatma, sonlandırma, boyama, zımparalama, çekiçle çakma vb). Teknik hareket sıklı̆̆l ise bir dakikada yapılan teknik hareket sayısıdır. Teknik hareket sıklığı ve önerilen sıklık değerleri aşağıdaki formüllerle hesaplanır:

\section{Teknik hareket sıklı̆̆l = Bir çevrimdeki teknik hareket sayısı*60/çevrim süresi (2)}

Önerilen sıklık $=S S^{*} P^{*} T^{*} K^{*} E R F^{*}\left(D P^{*} T i S\right)$

Yukarıdaki denklemde kısaltmaları yer alan 7 parametre sirasiyla sabit siklik $(S S)$, postur $(P)$, tekrarlılık $(T)$, kuvvet $(K)$, ek risk faktörleri $(E R F)$, yetersiz dinlenme periyodu $(D P)$ ve tekrarlı işlerin bir vardiyadaki toplam süresidir (TIS). $S S$ çarpanı sabit bir değerdir [4]. Ancak bunun dişındaki diğer tüm çarpanlar 0-1 arasında bir değer alır. Bu değerler ideal koşullarda 1'dir ve ergonomik risk seviyesi arttıkça 0'a yaklaşır. Tüm bu çarpanlar aşağıda sırasıyla açıklanmıştır.

\subsection{Sabit Sıklık Çarpanı (Constant of Frequency Multiplier)}

Önerilen sıklık denklemindeki ilk çarpan olan $S S$ değeri bir çevrimdeki teknik hareketlerin sıklığıdır ve dakikada 30 hareket olarak kabul edilir [4].

\subsection{Postur Çarpanı (Posture Multiplier)}

Postur, operatörün teknik hareketleri yapmak için kullandığı vücut uzuvlarının pozisyonları ve hareketleridir. Vücut duruşlarının ve hareketlerinin analizinde dört temel üst vücut uzvu dikkate alınır: el, bilek, dirsek ve omuz. Bu uzuvların hem çalışma duruşları hem de bir çevrimde ne kadar süreyle çalıştıkları analiz için önemlidir. Her bir teknik hareket için postur analizi ve değerlendirmesi yapılması gerekir. Bu değerlendirme sağ ve sol vücut için ayrı ayrı yapılmalıdır. Ekteki şekilde omuz, dirsek bilek ve el için uygunsuz duruş ve hareketlere örnekler verilmiştir. Ekte detayları verilen uygunsuz çalışma duruşları kadar ne kadar süreyle bu pozisyonda çalışıldığ 1 da postur çarpanını hesaplamada önemlidir. Çevrim süresi boyunca uygunsuz duruşa maruz kalma oranı arttıkça risk faktörü de artar; dolayısıyla çarpan değeri sıfıra yaklaşır. Tablo 1'de uygunsuz duruş ve hareketlerin 
çevrim süresindeki ağırlığına göre belirlenen postur çarpanı değerleri verilmiştir. Bu tabloya göre örneğin, $60^{\circ}$ 'den fazla bir açıyla dirseğini bükerek çalışan bir işçi, eğer bu işlemi çevrim süresinin yarısından daha kısa bir zamanda tamamlıorsa ilgili postur çarpanı 1 olurken, çevrim süresinin \%80'inden fazla bu işle meşgul oluyorsa ilgili postur çarpanı 0,5 olur. Uygunsuz duruş ve hareketlerin analizini yaptıktan sonra, Tablo 1 kullanılarak her bir uzuv için ayrı-ayrı $P$ değerleri bulunur. Bulunan değerlerden en küçüğü OCRA indeksini hesaplamada kullanılacak olan $P$ postur çarpanı olarak seçilir. Tabloda bahsi geçen üst vücut uzuvlarıyla ilgili açılardan daha düşük derecede bir açıyla duruş ya da hareket yapılması durumunda uygunsuz postur durumu yoktur ve $P$ çarpanı 1 değerini alır.

Tablo 1. Uygunsuz duruş ve hareketlerin çevrim süresindeki ağırlığına göre belirlenen postur çarpanı değerleri (Posture multiplier related to awkward postures and their corresponding cycle time percents)

\begin{tabular}{|c|c|c|c|c|}
\hline \multirow[b]{2}{*}{ Uygunsuz duruş } & \multicolumn{4}{|c|}{ Çevrim süresi yüzdesi } \\
\hline & $\begin{array}{l}\% 1- \\
\% 24\end{array}$ & $\begin{array}{l}\% 25- \\
\% 50\end{array}$ & $\begin{array}{c}\% 51- \\
\% 80\end{array}$ & $>\% 80$ \\
\hline $\begin{array}{l}\text { Dirsekten döndürme } \\
\left(\geq 60^{\circ}\right)\end{array}$ & \multirow{3}{*}{1} & \multirow{3}{*}{0,7} & \multirow{3}{*}{0,6} & \multirow{3}{*}{0,5} \\
\hline $\begin{array}{l}\text { Bileği içe veya dişa } \\
\text { bükme }\left(\geq 45^{\circ}\right)\end{array}$ & & & & \\
\hline $\begin{array}{l}\text { Elle kıstırarak veya } \\
\text { kenarından/ sapından } \\
\text { veya avuçla tutma }\end{array}$ & & & & \\
\hline $\begin{array}{l}\text { Dirsekten döndürme } \\
\text { veya bükme / uzanma } \\
\left(\geq 60^{\circ}\right)\end{array}$ & \multirow{3}{*}{1} & \multirow{3}{*}{1} & \multirow{3}{*}{0,7} & \multirow{3}{*}{0,5} \\
\hline $\begin{array}{l}\text { Bileği yana dişa veya } \\
\text { yana içe döndürme } \\
\left(\geq 20^{\circ}\right)\end{array}$ & & & & \\
\hline $\begin{array}{l}\text { Elle dar cismi } \\
\text { kuvvetli tutma }(\leq 2 \mathrm{~cm})\end{array}$ & & & & \\
\hline
\end{tabular}

\subsection{Tekrarlılık Çarpanı (Repetitiveness multiplier)}

Tekrarlılık, operatör tarafından sürekli olarak aynı teknik hareketlerin yapılması durumudur. Tekrarlılık parametresi düşük ve yüksek olmak üzere ikiye ayrılır. Bir işin düşük tekrarlılıkta kabul edilebilmesi için çevrim süresinin 15 sn.den büyük olması ya da aynı tip teknik hareketlerin çevrim süresinin $\% 50$ 'sinden daha fazla tekrarlanmaması gerekir. $\mathrm{Bu}$ durumda $T$ değeri 1'e eşittir. Bunların dışındaki durumlarda ise yüksek tekrarlılık var demektir ve $T$ çarpanı 0,7 değerini alır $[4,8,11,12]$.

\subsection{Kuvvet Çarpanı (Force Multiplier)}

Kuvvet, operatörün teknik hareketleri yapmak için harcadığı fiziksel güçtür. Güç kullanımını gerektiren hareketler dinamik ya da statik olabilir. Sürekli olarak güç kullanımı gereken durumlar, KISH açısından risk faktörü oluşturur. Ayrıca, literatürde özellikle tendon ve sinirlerle ilgili meslek hastalıklarını, teknik harekelerin sıklığının ve teknik hareketlerde kullanılan gücün ortaklaşa etkisinin tetiklediği belirtilmiştir. Uygulanan kuvvetin risk faktörü olarak OCRA indeksine etkisi $K$ kuvvet çarpanı ile gösterilir. Kuvvet uygulanmasının gerekmediği durumlarda $K$ çarpanı 1 değerini alır. Kuvvet gerektiren durumlarda ise ortalama harcanan gücün bir fonksiyonu olarak $K$, Tablo 2'deki değerleri alır.

Tablo 2. Çeşitli kuvvet uygulamaları için $K$ kuvvet çarpanı değerleri (Multiplier relative to the different use of force)

\begin{tabular}{|l|c|c|c|c|c|c|}
\hline $\begin{array}{l}\text { Ortalama } \\
\text { harcanan } \\
\text { kuvvet } \\
(\%)\end{array}$ & 5 & 10 & 20 & 30 & 40 & $\geq 50$ \\
\hline $\begin{array}{l}\text { Borg } \\
\text { değeri }\end{array}$ & 0,5 & 1 & 2 & 3 & 4 & $\geq 5$ \\
\hline Değer & $\begin{array}{c}\text { çok } \\
\text { çok } \\
\text { zayıf }\end{array}$ & $\begin{array}{c}\text { çok } \\
\text { zayıf }\end{array}$ & zayıf & orta & $\begin{array}{c}\text { biraz } \\
\text { kuv- } \\
\text { vetli }\end{array}$ & $\begin{array}{c}\text { Kuvvetli } \\
\text { /çok } \\
\text { kuvvetli }\end{array}$ \\
\hline $\begin{array}{l}\text { Kuvvet } \\
\text { çarpanı } \\
(F)\end{array}$ & 1 & 0,85 & 0,65 & 0,3 & 0,2 & 0,01 \\
\hline
\end{tabular}

Pratikte uygulanan kuvvet miktarının belirlenmesi kolay değildir. Bu amaçla bilim insanları niteliksel ve niceliksel birçok farklı yöntemle kuvveti ölçmeye çalışmışlardır. Bunlardan en yaygın olarak kullanılanı Borg ölçeğidir [2] ve Tablo 2'nin ikinci satırında yer almaktadır. Ayrıca literatürde yer alan bazı çalışmalarda da üçüncü satırda yer alan gözleme dayalı ölçeklendirme yapılmaktadır. Yukarıdaki tabloda yer alan değerlerden interpolasyon yaparak, bu değerler arasındaki kuvvet uygulamaları için $K$ değeri hesaplanabilir.

\subsection{Ek risk Faktörleri Çarpanı (Additional Risk} Factors Multiplier)

Diğer temel risk faktörlerinin (postur, tekrarlılık, kuvvet, yetersiz dinlenme periyodu, tekrarlı işlerin bir vardiyadaki toplam süresi) dışında ergonomik açıdan risk oluşturabilecek ek faktörlerdir. Ek faktörler olarak tanımlanmalarının nedeni, ikinci derecede önemli olmalarından değil, bu faktörlerin zamanzaman ortaya çıkmalarından kaynaklanmaktadır. Bu faktörlerden bazıları şunlardır: titreşim yapan araç gereç kullanımı; hassas yerleştirme gereken durumlar (1-2 mm toleransla yerleştirilen cisimler); bazı vücut bölgelerine lokal olarak kuvvetli basınç uygulanması; yetersiz ya da aşırı sıcaklık; yetersiz ya da aşırı ışık; gürültü; tutma/kavrama gibi işlemler sırasında eldiven takılmasının gerekmesi; ani ve çok hızlı hareket edilmesi gereken durumlar; konveyör ya da makine sebebiyle çok yüksek hızda çalışmak zorunda olma; çalışılan nesnenin keskin kenarlı olması vb...

Yukarıda bahsi geçen durumlar, eğer işin büyük çoğunluğunda oluşmuyorsa, $E R F$ çarpanı 1 değerini alır. Diğer durumlarda ERF'ne maruziyetin çevrim süresindeki payına göre bu değer giderek azalır. $E R F$ 'ne maruziyet eğer çevrim süresinin $\% 25$ 'inden daha kısaysa $E R F=1 ; \% 26-\% 50$ arasındaysa, $E R F=$ 0,$95 ; \% 51-\% 80$ arasındaysa, $E R F=0,90$ ve eğer $\% 80$ 'inden fazlaysa, $E R F=0,80$ olur. 


\subsection{Yetersiz Dinlenme Periyodu ve Tekrarlı İşlerin Vardiyadaki Süresi Çarpanları (Lack Of Recovery Period And Number of Technical Actions in A Shift Multiplier)}

Dinlenme periyodu hareketler yaptıktan sonraki, insan vücudunun kendini toparlaması için gereken zamandır. Örneğin, 480 dakikalık bir vardiyada bir öğle yemeği molası ve biri sabah biri öğleden sonra olmak üzere 10'ar dakikalık 2 adet çay molası olduğu durumda ideal çalışma koşulları oluşturulmuş olur. $D P$ ve TIS çarpanlarının OCRA indeksine etkisi, diğer çarpanlardan farklı olarak, yapılan işe göre değişiklilik göstermez. Bu nedenle bu çarpanları tüm işler için ortak birer sabit gibi kabul edebiliriz. İdeal çalışma koşullarının olduğu durumda $D P$ ve $T I S$ çarpanları sırasıyla 0,6 ve 1 değerlerini alırlar.

\subsection{OCRA İndeksi Değerinin Yorumlanması (Interpreting the OCRA index)}

Yukarıda bahsedilen değerlendirmeler yapılıp nihai OCRA indeksi (1) numaralı denklemden elde edilir. OCRA indeks değerinin 2,2'den küçük olduğu durumda istasyon ergonomik anlamda yeterlidir demektir (yeşil bölge). Değerin 2,2-3,5 arasında olduğu durumda ise ergonomist, istasyonu analiz ederek şartlı olarak kabul edebilir (sarı bölge). Değerin 3,5'un üzerinde olduğu durumda ise istasyondaki ergonomik risk düzeyi kabul edilemez demektir ve acilen düzeltmeler yapılmalıdır (kırmızı bölge).

\section{OCRA INDEKSİ KULLANILARAK ERGONOMIK RİSK FAKTÖRLERİ ANALIZİ: BİR ÖRNEK (ERGONOMIC RISK ASSESSMENT BY USING OCRA INDEX: AN EXAMPLE)}

OCRA indeksinin nasıl hesaplandığı bir önceki bölümde detaylıca anlatılmıştır. Daha anlaşılır olması açısından, bu bölümde örnek bir montaj hattı üzerinde sayısal verilerle hesaplamalar yapılacaktır. Şekil 1'de örnek probleme ait montaj diyagramı yer almaktadır. Daire içindeki rakamlar işlerin numaralarını, daire dışındaki rakamlar ise işlem sürelerini vermektedir (1. işin işlem süresi $15 \mathrm{sn}$., 2 işin işlem süresi $13 \mathrm{sn}$. vb...). Hattın çevrim süresi mevcut durumda 160 sn. olmakla birlikte, bu sürenin \%10'u kadar artması üretimde bir sorun yaratmamaktadir.

Tablo 3'te örnek probleme ait OCRA parametreleri yer almaktadır. Tabloda yer almayan $S S, D P$ ve $T I S$ parametreleri ișten işe değișiklik göstermediğinden bu üç parametre doğrudan (3) numaralı formülde kullanılabilir. İdeal çalışma koşularında çalışıldığ 1 düşünülürse $S S=30, D P=0,6$ ve $T \dot{S} S=1$ olur. Ayrıca $T$ çarpanı da, aynı tip teknik hareketler çevrim süresinin \%50'sinden daha fazla tekrarlandığ 1 için tüm işler için 0,7 değerini alır. İşten işe değişkenlik gösteren tüm çarpanlar tabloda bulunmaktadır.

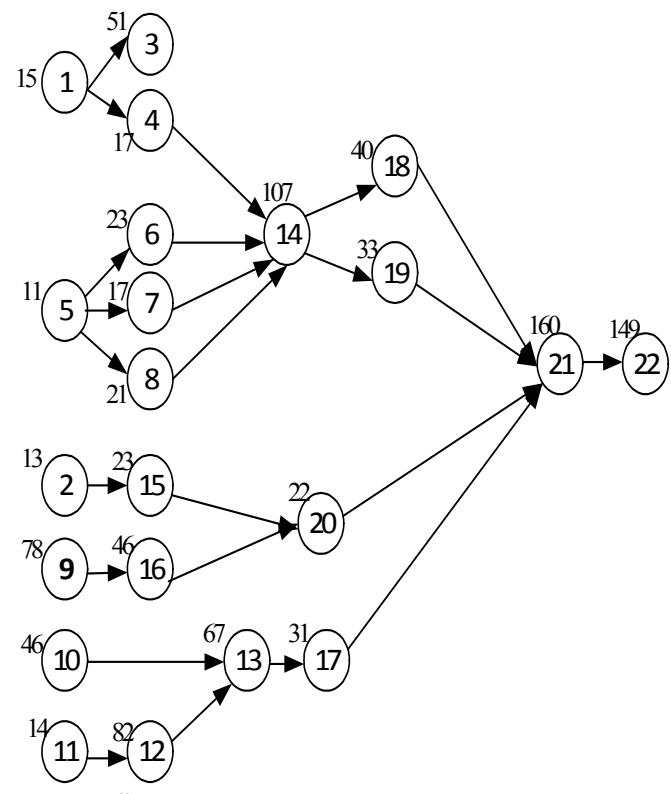

Şekil 1. Örnek probleme ait montaj diyagramı (Assembly diagram for the example)

OCRA indeksi hesaplanırken sağ ve sol için ayrı-ayrı hesaplanmalıdır. Bulunan iki OCRA değerinden hangisi daha yüksekse, diğer bir deyişle, daha kötü ergonomik koşulları ifade ediyorsa, o değer istasyonun OCRA değeri olarak belirlenmelidir. İşlemlerin gösterimine örnek oluşturması amacıyla bu çalışmada yalnızca sağ vücut için hesaplamalara yer verilmiştir.

Bahsi geçen hat mevcut durumda 7 istasyondan oluşmakta ve istasyonlarda sırasıyla şu işler yapılmaktadır: 1. istasyonda $1,3,4,5,6,7$ ve 8 . işler; 2 . istasyonda $2,9,10$ ve 11 . işler; 3 . istasyonda 14 ve 18. işler; 4. istasyonda 12 ve 13 . işler; 5 . istasyonda $15,16,17,19$ ve 20 . işler; 6 . istasyonda 21 . iş ve 7 . istasyonda da 22. iş bulunmaktadır. Verilen tüm bu bilgiler 1şığında, öncelikle hattın ergonomik anlamda yeterli olup olmadığı incelenmelidir. Şekil 2'de mevcut durumda ve yeniden atama sonucunda istasyonlarda yapılan işler, istasyon zamanları ve OCRA indeksi değerleri yer almaktadır.

Mevcut durumda 1. istasyon için OCRA değerini hesaplayalım. 1. istasyonda yapılan toplam teknik hareket sayısı ve istasyon zamanı sirasıly, $73(14+8+12+6+11+11+11)$ $155(15+51+17+11+23+17+21)$ 'dir. Teknik hareket sıklığı, diğer bir deyişle bir dakikadaki teknik hareket say1s1 ise $28,26(73 * 60 / 155)$ olarak bulunur. Önerilen sıklığı hesaplayabilmek için ise öncelikle $S S, P, T, K$, $E R F, D P, T I S$ parametreleri belirlenmelidir. SS, T, DP ve TIS çarpanları bu örnekte her iş için sabittir. Sirasıyla $P, K$ ve ERF çarpanları da Tablo 3 'ten bulunur.

Tablo 3 'te verilen değerler sağ vücut için geçerlidir. 
Tablo 3. Örnek probleme ait OCRA parametreleri (OCRA parameters for the example)

\begin{tabular}{|c|c|c|c|c|c|c|c|c|c|}
\hline $\begin{array}{l}\text { İş } \\
\text { no }\end{array}$ & $\begin{array}{c}\text { Teknik } \\
\text { Hareket Sayısı }\end{array}$ & $P$ & $\begin{array}{c}\text { Ortalama } K \\
(\%)\end{array}$ & $E R F$ & $\begin{array}{l}\text { İş } \\
\text { no }\end{array}$ & $\begin{array}{c}\text { Teknik Hareket } \\
\text { Sayısı }\end{array}$ & $P$ & $\begin{array}{c}\text { Ortalama } K \\
(\%)\end{array}$ & $E R F$ \\
\hline 1 & 14 & 1 & 10 & 1 & 12 & 25 & 0,7 & 5 & 1 \\
\hline 2 & 12 & 1 & 10 & 1 & 13 & 23 & 1 & 5 & 1 \\
\hline 3 & 8 & 0,7 & 5 & 1 & 14 & 14 & 0,6 & 5 & 1 \\
\hline 4 & 12 & 1 & 5 & 1 & 15 & 26 & 1 & 5 & 1 \\
\hline 5 & 6 & 1 & 20 & 0,95 & 16 & 26 & 1 & 5 & 1 \\
\hline 6 & 11 & 1 & 5 & 1 & 17 & 14 & 1 & 5 & 1 \\
\hline 7 & 11 & 1 & 5 & 1 & 18 & 16 & 1 & 5 & 1 \\
\hline 8 & 11 & 1 & 5 & 0,95 & 19 & 25 & 1 & 5 & 1 \\
\hline 9 & 14 & 0,6 & 15 & 0,95 & 20 & 28 & 1 & 5 & 1 \\
\hline 10 & 11 & 0,7 & 10 & 0,95 & 21 & 38 & 0,5 & 5 & 1 \\
\hline 11 & 12 & 1 & 10 & 1 & 22 & 33 & 0,5 & 5 & 1 \\
\hline
\end{tabular}

\begin{tabular}{|cccc|}
\hline Ist. no & Iș & OCRA Indeksi Ist. Zamann \\
\hline 1 & $1,3,4,5,6,7,8$ & 3.6 (Kırmız1) & 155 \\
\hline 2 & $2,9,10,11$ & 3.4 (Sar1) & 151 \\
\hline 3 & 14,18 & 1.6 (Yeşil) & 147 \\
\hline 4 & 12,13 & 2.2 (Sar1) & 149 \\
\hline 5 & $15,16,17,19,20$ & 3.7 (Kırmızı) & 155 \\
\hline 6 & 21 & 2.3 (Sar1) & 160 \\
\hline 7 & 22 & 2.1 (Sar1) & 149 \\
\hline
\end{tabular}

2.a)

\begin{tabular}{|cccc|}
\hline Ist. no & Is & OCRA Indeksi Ist. Zaman! \\
\hline 1 & $1,5,7,8$ & 3.3 (San) & 115 \\
\hline 2 & $2,9,10,11$ & 3.4 (Sarn) & 151 \\
\hline 3 & $4,14,18$ & 2.0 (Sarn) & 164 \\
\hline 4 & $6,12,13$ & 2.3 (Sarn) & 172 \\
\hline 5 & $15,16,17,19$ & 3.3 (Sarn) & 133 \\
\hline 6 & 21 & 2.3 (Sarn) & 160 \\
\hline 7 & 20,22 & 3.4 (Sarn) & 171 \\
\hline
\end{tabular}

2.b)

Şekil 2. Montaj hattının başlangıç durumu ve yeniden dengeleme sonrası durumu (The present situation and the situation after rebalancing of the assembly line)

İșlerin içeriklerine örnek oluşturması amaciyla yalnızca 1. istasyondaki işler verilmiştir: $1,3,4,5,6$, 7 ve 8 . işlerin çalışma duruşları sırasıyla şunlardır: el ile dar bir cismi kıstırarak tutma, el ile geniş bir cismi avuçla tutma, dirsekten döndürme (uygunsuz postur $>$ $60^{\circ}$ ), dirsekten bükme (uygunsuz postur $>60^{\circ}$ ), bileği yana dişa döndürme (uygunsuz postur $>20^{\circ}$ ), bileği içe bükme (uygunsuz postur $>45^{\circ}$ ) ve el ile dar bir cismi kıstırarak tutma. Örneğin 3. işteki çalışma duruşu el ile geniş bir cismi avuçla tutmadır ve istasyon zamanının \%33' ü (51/154) boyunca bu pozisyonda çalışılmaktadır. Tablo 1'den bakılarak ilgili postur çarpanının 0,7 olduğu bulunur. Diğer tüm işler için de aynı şekilde tablo 1'den yararlanılarak ilgili postur değerleri bulunur. 1. İstasyondaki tüm işlerin $P$ değerleri sırasıyla 1, 0,7,1,1,1,1 ve 1'dir. İstasyonun $P$ değeri ise istasyondaki tüm işler içerisinde en küçük $P$ çarpanına sahip olan işin değeridir. Bunun sebebi, istasyonun ergonomik durumunu en kötü senaryoya göre belirleyebilmektir. $\mathrm{Bu}$ durumda istasyonun $P$ değeri 0,7'dir. Benzer şekilde, istasyonun $E R F$ değeri de en küçük $E R F$ çarpanına sahip olan işin değeridir ve 1 . istasyon için 0,95 ' dir. İstasyona ait $F$ çarpanını belirleyebilmek için öncelikle istasyonda harcanan ortalama kuvvet hesaplanmalıdır:

$$
\begin{aligned}
& (15 / 155) * 10+(51 / 155) * 5+(17 / 155) * 5+ \\
& \cdots+(21 / 155) * 5 \cong 7
\end{aligned}
$$

Tablo 2'den interpolasyon yapılarak ilgili $F$ değeri $0,94(1-(0,15 / 5) * 2)$ olarak bulunur. Tüm parametreler belirlendikten sonra sağ taraf için OCRA indeksi şu şekilde hesaplanır:

Önerilen sıklık $=S S * P * T * K^{*} E R F^{*}(D P * T I S)$

Önerilen s1kl1k $=30 * 0,7 * 0,7 * 0,94 * 0,95 *(0,6 * 1)=7,88$

OCRA indeksi $=$ Teknik hareket sıklığ 1 Önerilen siklık $=28,26 / 7,88=3,6$

$\mathrm{Bu}$ durumda bu istasyon kırmızı bölgededir ve bu haliyle istasyon ergonomik anlamda kabul edilemez, acilen iyileştirmeler yapılması gerekmektedir. Mevcut durum için tüm istasyonların OCRA indeksleri hesaplanılarak Şekil 2.a'da gösterilmiştir. Şekilden de görüleceği gibi iki istasyonun değeri red bölgesindedir (kırmızı) ve hattın yeniden dengelenerek ergonomik anlamda yeterli koşullara ulaştırılması gerekmektedir.

Giriş kısmında da belirtildiği gibi iş istasyonu sayısının sabit olduğu ve çevrim süresinin en küçüklenmeye çalışıldığı MHDPleri 2. tip problem sınıfına girer. $\mathrm{Bu}$ örnekte de işletme koşullarından dolayı istasyon sayısı sabit bir değerdir. Tüm işler toplamda 7 istasyona atanmış olmalıdır. $\mathrm{Bu}$ nedenle karşılaşılan problem MHDP-II'dir. 
Mevcut çalışmada amaç bir ergonomik risk değerlendirme yöntemi olan OCRA indeksini tanıtmak ve örnek bir montaj hattı üzerinde istasyon sayısı arttırılmadan yalnızca işleri yeniden atayarak ergonomik risk seviyesinin azaltılabileceğini göstermektir. $\mathrm{Bu}$ amaçla örnek problem son derece basit bir şekilde literatürde COMSOAL yaklaşımı olarak bilinen yöntemle çözülmüştür. Bu yaklaşıma göre, öncelik ilişkilerine uyan ve çevrim süresini aşmayan işler atanabilir işler kümesine koyularak, atanabilir işlerin içerisinden rastgele işleri birer-birer seçip mevcut istasyona atamak gerekir. Çözüm yöntemine ait akış şeması Şekil 3'te gösterilmiştir. Önerilen çözüm yöntemi son derece basit bir yöntem olduğu halde olurlu çözüm bulmaktadır. Burada iddiamız optimum sonucu elde etmek değil, istasyon sayısını arttırmadan daha iyi OCRA değerleri içeren olurlu bir çözüm bulmaktır. Bu nedenle, algoritma 100 defa çalıştırılarak farklı sonuçlar elde edilir ve verilen örnekteki gibi mevcut durumdan daha düşük risk seviyelerine sahip bir çözüm elde edilir.

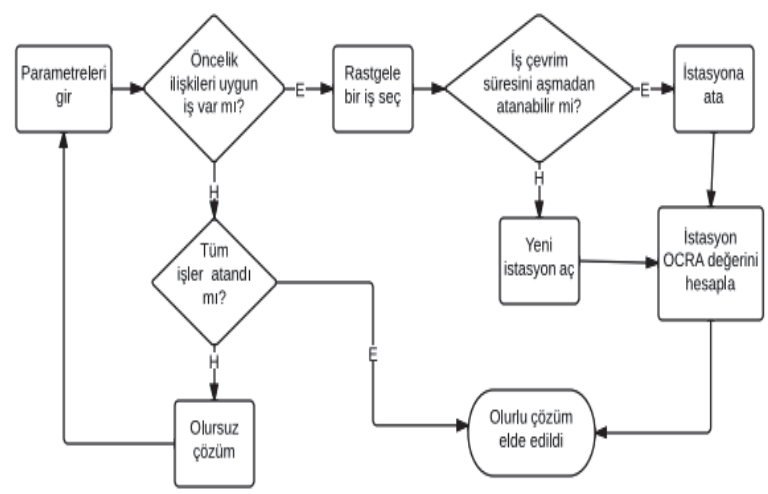

Şekil 3. COMSOAL yaklaşımının akış şeması (flowchart of the COMSOAL approach)

Yapılan yeniden dengeleme sonucunda işlerin istasyonlara dağılımı, istasyonların OCRA indeks değerleri ve istasyon zamanları Şekil 2.b'de yer almaktadır. Buradan da görüleceği gibi, yeni durumda iş istasyonu sayısı arttırılmadan yalnızca sarı istasyonlardan oluşan bir hat tasarlanmıştır. Bütün istasyonlar ergonomik çalışma ortamı açısından kabul edilebilir risk seviyesindedir. Çalışma ortamındaki ergonomik koşulların iyileştirilmesi, işçilerin üzerindeki yorgunluğun azalması, fire/hurda oranlarının azalması, verimliliğin artması gibi çok olumlu sonuçlar doğuracaktır. Örnek problemde de görüldüğü gibi bu faydaları sağlayan çözümleri üretmek için istasyon sayılarının arttırılması da gerekmeyebilir.

\section{SONUÇ (CONCLUSION)}

Montaj hattı dengeleme probleminde iş yüklerinin istasyonlara düzgün dağıtılması kadar, çalışma duruşlarından kaynaklanan zorlanma derecelerinin de düzgün dağıtılması son derece önemlidir. Aksi takdirde, bazı istasyonlara haddinden fazla zorlukta işler yüklenebilir ve bu durum çalışma ortamındaki ergonomik risk faktörlerini artırır. Ergonomik açıdan uygun olmayan çalışma koşulları, beraberinde işgücünde verimlilik azalmaları, fire/hurda oranlarında artış gibi dolaylı maliyetleri getirmekte ve işletmeleri günümüz modern rekabet koşullarında zayıflatmaktadır. $\mathrm{Bu}$ nedenle, işleri istasyonlara atarken, istasyonlardaki ergonomik risk faktörlerinin belirli bir seviyenin üstüne çıkmasını engellemek gerekmektedir.

$\mathrm{Bu}$ çalışmada, işlerin yarattığı ergonomik risk faktörlerinin etkisini kümülatif olarak dikkate alan ve özellikle emek yoğun montaj hatlarının ergonomik değerlendirmesinde kullanılması uygun olan OCRA indeksi yöntemi tanıtılmıştır. Yöntemin çalışma prensipleri detaylı bir şekilde anlatılarak, örnek bir montaj hattı istasyonu üzerinde sayısal hesaplamalar yapılmıştır. Yapılan hesaplamalar sonucunda istasyonun OCRA indeks değeri oldukça yüksek çıkmış ve istasyonda acilen ergonomik yaptırımlarda bulunulması gerektiği belirtilmiştir. Firmalar yoğun rekabet ortamında talebe hızlı bir şekilde cevap verebilmek için hattan mümkün olan en fazla ürün çıktısını almak isterler. Oysaki bu düşünce kısa vadeli bir düşüncedir. Verilen örnekte de görüldüğü gibi düzgün dengelendiği zannedilerek çalıştırılan bir montaj hattı aslında ergonomik anlamda büyük riskler taşıyor olabilir. $\mathrm{Bu}$ durumda, uzun vadede oluşacak işgücü kayıplarından dolayı verimlilik kayıpları oluşur. $\mathrm{Bu}$ sebeple, uzun vadeli planlar yapan, geleceği gören işletmeler, çalışma ortamının ergonomik koşullarına önem vermeye mecburdurlar. Üstelik örnek problemde de görüldüğü gibi, uygun atamalar yapıldığında ergonomik iyileştirmeleri yapmak için mutlaka ek bir istasyon açılmasına da gerek kalmayabilmektedir.

\section{EK (APPENDIX)}

Şekil E'de uygunsuz çalışma duruş ve hareketlerine örnek şekiller verilmiştir. 1.a - 1.c arası duruşlar omuz, 2.a - 2.b dirsek, 3.a - 3.d bilek ve 4.a - 4.b el duruş ve hareketlerini ifade etmektedir.

\section{KAYNAKLAR (REFERENCES)}

1. Battini, D., Faccio, M., Persona, A. ve Sgarbossa, F., "Linking Ergonomics Evaluation and Assembly System Design Problem in a New Integrated Procedure", In the Proceedings of the 19th International Conference on Production Research, Valparaiso/Şili, 29 Haz.-2 Ağus. 2007.

2. Borg, G.A.V., "A category scale with ratio properties for intermodal and interindividual comparison", Psychophysical Judgement and the Process of Perception, Editör: Geissler, H.G. ve Petzold, P., VEB Deutscher Verlag der Wissenschaften, Berlin, 25-34, 1982.

3. Çalıșma ve Sosyal Güvenlik Bakanlığı İș Sağlığı ve Güvenliği Genel Müdürlüğü (İSGGM), Meslek Hastalıkları Rehberi, Berk, M., Önal, B. ve Güven, R., Matsa Basımevi, Ankara, 2011.

4. European Committee for Standardization, EN 1005-5 Safety of Machinery - Human Physical 
Performance - Part 5: Risk Assessment for Repetitive Handling at High Frequency, Management Centre, Brüksel, Belçika, 2007.

5. Fişek, A.G., "Yeni Dönemde (6331 s.k. sonrası) Değerlendirmeler - 1", Çalışma Ortamı, Cilt 130, 8-12, 2013.

6. Longo, F. ve Mirabelli, G., "Effective Design of an Assembly Line using Modeling and Simulation", Journal of Simulation, Cilt 3, No 1, 50-60, 2009.

7. Occhipinti E., "OCRA: A Concise Index for the Assessment of Exposure to Repetitive Movements of Upper Limbs", Ergonomics, Cilt 41, No 9, 1290-1311, 1998.

8. Otto, A. ve Scholl, A., "Incorporating Ergonomic Risks into Assembly Line Balancing", European Journal of Operational Research, Cilt 212, No 2, 277-286, 2011.
9. Moreau M., "Corporate Ergonomics Programme at Automobiles Peugeot-Sochaux", Applied Ergonomics, Cilt 34, No 6, 29-34, 2003.

10. Salveson, M.E., "The Assembly Line Balancing Problem", Journal of Industrial Engineering, Cilt 6, No 3, 18-25, 1955.

11. Silverstein, B.A., Fine, L.J. ve Armstrong, T.J., "Hand wrist cumulative trauma disorders in industry", British Journal of Industrial Medicine, Cilt 43, No11, 779-784, 1986.

12. Silverstein, B.A., Fine, L.J. ve Armstrong, T.J., "Occupational factors and carpal tunnel syndrome", American Journal of Industrial Medicine, Cilt11, No3, 343-358, 1987.

13. Vieira, E.R. ve Kumar, S., "Working Postures: A Literature Review", Journal of Occupational Rehabilitation, Cilt 14, No 2, 143-159, 2004.

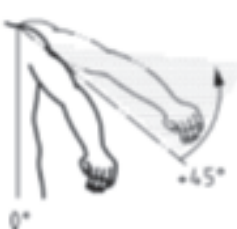

1.a)

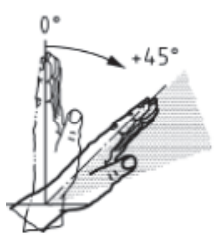

3.a)

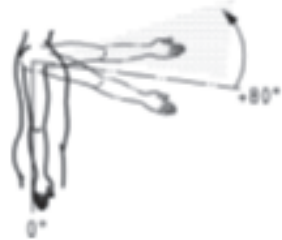

1.b)

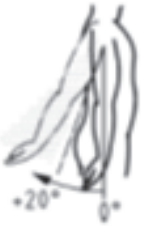

1.c)

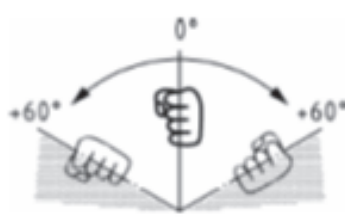

2.a)

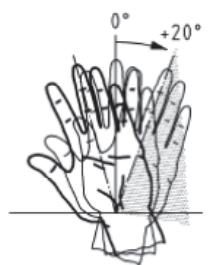

3.c)

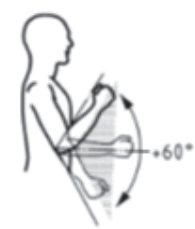

2.b)

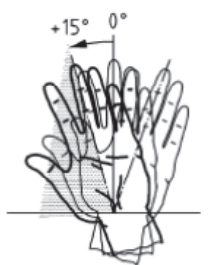

3.d)

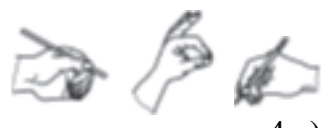

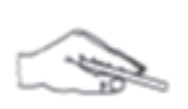

.a)

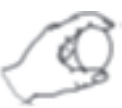

Şekil E. Uygunsuz duruş ve hareketler (awkward postures and movements)

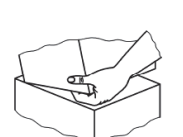

4.b)
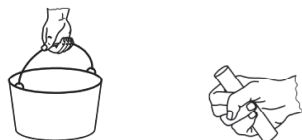

4.c)

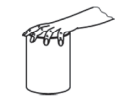

4.d)

1.a)Yan kaldırma/indirme/çekme (uygunsuz postur $>45^{\circ}$ ) (Lateral elevation abduction/adduction (awkward posture $>45^{\circ}$ )) 1.b)Ön kaldırma/uzanma (uygunsuz postur $>80^{\circ}$ ) (Frontal elevation flexion (awkward posture $>80^{\circ}$ )) 1.c)Geriye uzanma (uygunsuz postur $>20^{\circ}$ ) (Extension (awkward posture $\left.>20^{\circ}\right)$ )

2.a)Dirsekten döndürme (uygunsuz postur $>60^{\circ}$ ) (prono suppination (awkward posture $>60^{\circ}$ )) 2.b)Bükme / uzanma (uygunsuz postur $>60^{\circ}$ ) (flexion, extensionoint (awkward posture $\left.>60^{\circ}\right)$ )

3.a)İçe bükme (uygunsuz postur $>45^{\circ}$ ) $\left(\right.$ Palmarflexion(awk.post $>45^{\circ}$ )) 3.b)Dışa bükme (uygunsuz postur $>45^{\circ}$ ) (Dorsal extension(awk.post $>45^{\circ}$ )) 3.c)Yana dişa döndürme (uygunsuz postur $>20^{\circ}$ ) (Ulnardeviation(awk.post $>20^{\circ}$ )) 3.d) içe döndürme (uygunsuz postur $>15^{\circ}$ ) (Radial deviation (awkpost $\left.>15^{\circ}\right)$ )

4.a) Kistırarak tutma (pinch) 4.b) Kenarından/sapından tutma (hook grips) 4.c) Kuvvetli tutma (power grip) 4.d) Avuçla tutma (palmar grip) 